\title{
ANTONIO TABUCCHI: LEITOR E TRADUTOR DE Carlos Drummond de Andrade
}

\author{
Erica Salatin ${ }^{*}$
}

RESUMO: Em 1987 foi publicada na Itália a primeira coletânea de poemas de Carlos Drummond de Andrade, com tradução de Antonio Tabucchi, importante escritor contemporâneo, lusitanista e tradutor. Antes disso o leitor italiano só teve acesso a poemas esparsos de Drummond, publicados em antologias de poetas brasileiros. Este artigo apresenta brevemente a tradução de dois destes poemas e reflete sobre as escolhas do tradutor, acenando para as implicações desta tradução de Tabucchi na divulgação da obra poética drummondiana no contexto literário italiano. PALAVRAS-CHAVE: Tabucchi; Drummond; tradução; poesia

ABSTRACT: Nel 1987 fu pubblicata in Italia la prima raccolta di poesie di Carlos Drummond de Andrade, nella traduzione di Antonio Tabucchi, importante scrittore contemporaneo, lusitanista e traduttore. Prima di questa raccolta, il lettore italiano aveva avuto accesso solo a poesie sparse di Drummond, pubblicate in antologie di poesia brasiliana. Questo articolo presenta brevemente la traduzione di due di queste poesie e riflette sulle scelte del traduttore, accennando alle implicazioni della traduzione di Tabucchi per la diffusione dell'opera poetica drummondiana nel contesto letterario italiano.

PAROLE-CHIAVE: Tabucchi; Drummond; traduzione; poesia.

ABSTRACT: In 1987 the first collection of poems by Carlos Drummond de Andrade was published in Italy, with translation by Antonio Tabucchi, an important

* Universidade Estadual Paulista, Campus de Assis, São Paulo (Brasil) - ericasalatini@gmail.com Processo n.2013/20971-0 Fundação de Amparo à Pesquisa do Estado de São Paulo (FAPESP)

DOI: http://dx.doi.org/10.11606/issn.2238-8281.v0i34p12-22 
contemporary writer, lusitanist and translator. Before that, the Italian reader had only access to Drummond's poems, published in anthologies of Brazilian poets. This article briefly presents the translation of two of these poems and reflects on the choices of the translator, waving to the implications of this translation of Tabucchi in the dissemination of Drummondian poetry in the Italian literary context.

KEYWORDS: Tabucchi; Drummond; translation; poetry. 


\section{Tabucchi leitor de Drummond}

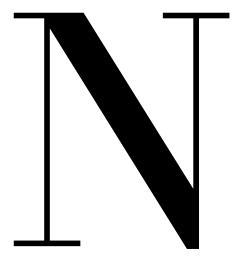

o início dos anos de 1980, o escritor Antonio Tabucchi, em viagem ao Brasil, teve a oportunidade de conhecer o poeta brasileiro Carlos Drummond de Andrade e mostrar-lhe a tradução em italiano que havia feito de alguns de seus poemas. Estes poemas foram reunidos mais tarde na coletânea Sentimento del mondo, publicada pela editora Einaudi, no ano de 1987. Neste livro, o escritor italiano traduziu 37 poemas do poeta brasileiro, apresentando-o ao público italiano. Diz Tabucchi que, com a escolha destes poemas, tentou reter uma "immagine più leggibile, o più 'riconoscibile' di un poeta così vasto e così complesso come Drummond, che ha toccato i grandi temi della letteratura del nostro tempo e che la critica, unanimemente, riconosce come il maggior poeta contemporaneo di lingua portoghese insieme con Fernando Pessoa" (TABUCCHI, 1987, p. 5).

Antes de sua estreia como escritor de narrativas, que ocorre em 1975, com o lançamento de seu romance Piazza d'Italia, Tabucchi já havia publicado algumas traduções, em italiano, de poemas de autores de língua portuguesa, língua que conhece bem, devido a seus estudos de filologia românica, e de modo particular, de filologia ibérica. Além de tradutor, Tabucchi foi também divulgador de literaturas em língua portuguesa na Itália. 
Em relação à literatura brasileira, escreveu crônicas e artigos de jornais sobre Drummond, sobre Guimarães Rosa, João Cabral de Melo Neto, entre outros. Pode-se dizer que o autor italiano traduziu, com muita propriedade, dois dos maiores poetas modernos em língua portuguesa: Pessoa e Drummond. Não só os traduziu, como também os inseriu em sua própria obra narrativa. Pessoa se tornou personagem de várias ficções tabucchianas, sendo considerado por alguns dos críticos e estudiosos de Tabucchi um "alter-ego" ou um duplo do autor.

Como escritor, Antonio Tabucchi dedicou-se, sobretudo, à arte narrativa, mas sua paixão pela arte poética, a aproximação com a poesia, pode ser vista no citacionismo de vários poetas presente em sua obra e também em seu trabalho de tradutor, visto que traduz especialmente poemas para o italiano. Como tradutor, dedica-se à tradução de vários volumes das obras poéticas de Fernando Pessoa e da prosa inquieta de Bernardo Soares, traduz os surrealistas portugueses, além de Drummond. Traduz também alguns romances brasileiros como Zero, de Ignácio de Loyola Brandão (1974), Menino de engenho e Moleque Ricardo de José Lins do Rego (Il treno di Recife. Due romanzi, com prefácio de Luciana Stegagno Picchio, 1974).

Como autor contemporâneo, muitas vezes tido pela crítica como pós-moderno, Tabucchi se vale da intertextualidade e cita vários poetas em sua ficção; o maior exemplo é, como dissemos, a inserção da poesia de Fernando Pessoa em sua obra e, ainda mais, do poeta transformado em personagem em alguns de seus contos e romances. Este procedimento também ocorre, em menor medida, com a figura de Antero de Quental e de Alexandre O'Neill, para ficar entre os portugueses. Tabucchi, todavia, não cita só os poetas portugueses, também perpassam por sua narrativa citações e referências a Leopardi, Montale e Pasolini, entre os italianos, Calderón de la Barca e Antonio Machado, entre os espanhóis, os brasileiros Drummond de Andrade e João Cabral de Melo Neto, entre outros, de várias outras nacionalidades, para nomear alguns dos que são efetivamente citados em sua narrativa.

Drummond é citado em duas narrativas de Tabucchi: no conto "Notte, mare o distanza", do livro L'angelo nero, em que o título é a citação de um verso de um poema drummondiano ("e não se sabe se é noite, mar ou distância"), e no Post Scriptum a Donna di Porto Pim, "Una balena vede gli uomini", que faz referência ao poema Um boi vê os homens do poeta brasileiro. Estes textos não podem ser entendidos completamente sem estas referências a Drummond.

Da perspectiva dos estudos comparados e da tradução, a intertextualidade tabucchiana é produtiva, se consideramos que todos os textos estão ligados entre si, não podendo prescindir dos textos precedentes ou mesmo de seus contemporâneos (BASSNETT, 2003, p. 134): todos os 
textos fazem parte de um sistema literário que procede de outros sistemas e com eles se relaciona, sendo, por isso, conforme Octavio Paz, "traduções de traduções de traduções" (BASSNETT, 2003, p. 74).

Ainda sobre Drummond, Tabucchi não só traduz alguns de seus poemas, como também publica algumas crônicas em jornais, como, por exemplo, "Nostalgia di Drummond", publicada pela primeira vez no Corriere della sera, em 11 de agosto de 1999, depois republicada no livro Viaggi e altri viaggi, de 2010. A breve introdução à antologia de poemas de Drummond traduzidos por Tabucchi também aparece publicada como artigo autônomo na coletânea póstuma Di tutto resta un poco, organizada pela estudiosa Anna Dolfi. Coletânea que homenageia justamente a relação entre Tabucchi leitor/tradutor de Drummond, ao receber o título de um poema drummondiano também traduzido por Tabucchi.

O conjunto destes textos, as narrativas em que é citado e as crônicas sobre o poeta brasileiro derivam, em certa medida, das traduções que Tabucchi faz de seus poemas e constitui um rico material de estudo para investigar a relação entre as literaturas brasileira e italiana, se considerarmos a perspectiva dos estudos da tradução e da literatura comparada. Tabucchi estabelece com a tradução da poesia de Drummond, com suas narrativas e crônicas, um fecundo diálogo entre a cultura brasileira e a italiana, uma interlocução entre estes dois sistemas literários.

A coletânea de poemas de Drummond traduzidos por Tabucchi é a primeira a ser publicada na Itália, antes disso, o leitor italiano teve acesso apenas a poemas esparsos, publicados em antologias de poetas brasileiros. Após esta coletânea, são publicadas outras duas: Un Chiaro Enigma, em dois volumes, com tradução de Fernanda Toriello (Bari, Stampa Puglia), em 1987 e 1990 e La visita, organizada por Luciana Stegagno Picchio (Milano, Libri Scheiwiller), em 1996.

\section{Tabucchi tradutor de Drummond}

Como dissemos, Tabucchi escolheu 37 poemas de Drummond e os traduziu para o italiano. Escolheu três ou quatro poemas de cada uma das coletâneas publicadas entre 1930 e 1968, apresentando ao público leitor italiano alguns dos mais importantes poemas drummondianos: No meio do caminho, Poema de sete faces, José, Um boi vê os homens, entre outros. À sua seleção de poemas Tabucchi deu o título Sentimento del mondo, tradução do título de outro célebre poema e também do livro Sentimento do mundo de Drummond.

Deste livro particularmente, o terceiro de Drummond, publicado em 1940, Tabucchi traduziu apenas quatro poemas, o primeiro e o último, Sentimento do mundo e Noturno à janela do 
apartamento, e ainda outros dois: Canção de berço e Os mortos de sobrecasaca.

De acordo com a fortuna crítica brasileira, Sentimento do mundo assinala uma mudança de perspectiva na poesia drummondiana em relação aos dois livros anteriores: "O sentimento de pertencer a algo maior altera profundamente a disposição do sujeito, tocado agora pelo desejo de participação no mundo e consequentemente empenhado em sua transformação" (MOURA, 2012, p. 51). Este desejo de participação no mundo não passa despercebido ao tradutor, que resgata este "sentimento" com a seleção do poema e com o uso do título do poema para intitular também sua antologia.

De modo geral, Tabucchi permanece fiel ao texto traduzido e ao sentimento poético presente na poesia de Drummond, procurando manter, no italiano, o sentido e a forma do texto por meio do uso de palavras equivalentes e próximas do original em português. Escolhe poemas em que predominam versos livres, mas ainda assim, devido as suas escolhas lexicais, consegue manter praticamente o mesmo número de sílabas e, com isso, o ritmo não se perde na passagem do português para o italiano, como podemos notar na tradução do poema que dá título à coletânea:

\section{Sentimento do mundo}

Tenho apenas duas mãos e o sentimento do mundo, mas estou cheio de escravos, minhas lembranças escorrem e o corpo transige na confluência do amor.

Quando me levantar, o céu estará morto e saqueado, eu mesmo estarei morto, morto meu desejo, morto o pântano sem acordes.

\section{Sentimento del mondo}

Ho soltanto due mani

e il sentimento del mondo, ma sono pieni di schiavi,

i miei ricordi scorrono

e il corpo transige

nella confluenza dell'amore.

Quando mi alzerò, il cielo sarà morto e saccheggiato, io stesso sarò morto, morto il mio desiderio, morto il pantano senza accordi. 


\begin{tabular}{|c|c|} 
Os camaradas não disseram & I compagni non hanno detto \\
que havia uma guerra & che c'era una guerra \\
e era necessário & e che era necessario \\
trazer fogo e alimento. & portare fuoco e viveri. \\
Sinto-me disperso, & Mi sento disperso, \\
anterior a fronteiras, & anteriore a frontiere, \\
humildemente vos peço & umilmente vi chiedo \\
que me perdoeis. & che mi perdoniate. \\
Quando os corpos passarem, & \\
eu ficarei sozinho & Quando i corpi passeranno \\
desafiando a recordação & io resterò solo solo \\
que habitavam a barraca & capeggiando la memoria \\
e não foram encontrados & della guardia, della vedova e del microscopista \\
ao amanhecer & che abitavano la baracca \\
esse amanhecer & e non furono ritrovati \\
mais noite que a noite. & all'albeggiare \\
\hline
\end{tabular}

Como se vê, o tradutor se esforça por manter a proximidade com o português, fazendo escolhas lexicais que aproximam o poema italiano da linguagem drummondiana. $\mathrm{O}$ resultado é, todavia, uma sutil transposição de palavras de uma língua para outra, uma poesia mais comprometida com o original, mas talvez menos autêntica do ponto de vista do registro italiano. Como o próprio tradutor faz notar, é um exercício de tradução ao invés de uma "recriação" poética meditada, pensada. Pode-se dizer que o escritor italiano não se apropria do poema, de sua forma, recriando-o ou reinventando-o, mas procura passar ao leitor, sobretudo, o significado do conteúdo da obra do poeta brasileiro.

Tabucchi se compromete a transmitir ao leitor italiano o estilo, o tom e a linguagem característicos da poesia drummondiana, o que, segundo John Gledson, consiste nos três pilares 
em que se assentam a obra de Drummond, e que constituem a "novidade" de sua poesia, além de assinalar um "compromisso" e uma "aproximação da língua falada": "Há um compromisso entre linguagem literária e coloquial, entre humor e seriedade, entre obscuridade e clareza, entre indivíduo e sociedade" (GLEDSON, 2003, p. 281-2).

A tradução de Tabucchi parece primar pela manutenção deste compromisso, buscando no italiano uma forma poética ligada ao coloquial e à linguagem simples, o que se torna mais difícil quando a aproximação lexical é grande, pois alguns termos que no português fazem parte de uma linguagem coloquial, no italiano podem ser mais sofisticados e vice-versa, como, por exemplo, "albeggiare", que é uma forma literária. Já nos versos "e il corpo transige/nella confluenza dell'amore", o estranhamento no italiano, também ligado a uma linguagem pouco usual parece estar de acordo com o original em português, em que "transige" também é dissonante, usado metaforicamente. Este poema, em especial, usa uma terminologia ligada à guerra que reproduz uma época e um contexto específico. São dados dos quais o tradutor tem consciência e procura manter em sua versão, com resultados positivos, sempre considerando o desejo de aproximação com o original.

Podemos notar ainda que, como acentua Gledson sobre a tradução de Drummond para o inglês, a tradução para uma linguagem poética "existe como possibilidade, e como tarefa atraente, mas não será por isso fácil. Neste mundo de detalhes, de nuances, de ironia e de mudanças de tom, a habilidade e a perícia do tradutor têm de ser grandes". Ainda mais considerando que Drummond, em Sentimento do mundo "busca efeitos mais orquestrais, declarações quase coletivas. Há perigos imprevistos, e alguns amigos-da-onça” (GLEDSON, 2003, p. 283).

A importância e as dificuldades do exercício da tradução aparecem tematizadas na obra de Tabucchi, que se interessa pela poesia drummondiana também como base de reflexão sobre a linguagem e como motivo temático para a composição de suas narrativas. Podemos observar isso no conto "Notte, mare o distanza", do livro L'angelo nero, em que a tradução do poema Noturno à janela do apartamento é o motivo da conversa entre um poeta e alguns jovens, que discutem sobre a melhor forma de tradução de um verso de um poema (de Drummond). Esta conversa acontece em uma noite de 1969 , às vésperas da eleição que coloca no poder o substituto de Salazar durante o período da ditadura em Portugal e retoma um dado da realidade do escritor: um "sarau poético" em homenagem a Drummond, ao qual Tabucchi teria participado quando estava traduzindo o poeta brasileiro, conforme nota do tradutor. $\mathrm{O}$ evento é ambientado em um tempo e lugar diferente, mas recria a discussão acerca da poesia e sua tradução. O poema 
é usado não apenas como motivo temático mas também auxilia na composição da atmosfera do conto, como se Tabucchi quisesse recriar, em forma de prosa, o poema drummondiano. A tradução consiste, desta forma, em um exercício ou um laboratório fértil para a escrita narrativa de Tabucchi. Procedimento que o autor repetirá frequentemente em suas narrativas posteriores, utilizando outros poetas e poemas.

Observando o poema citado e sua tradução, também notamos a tentativa do tradutor de se aproximar do conteúdo do poema, sem muita preocupação formal, fazendo escolhas lexicais ainda bastante próximas do português:

\section{Noturno à janela do apartamento}

Silencioso cubo de treva: um salto, e seria a morte

Mas é apenas, sob o vento, a integração na noite.

Nenhum pensamento de infância, nem saudade nem vão propósito.

Somente a contemplação de um mundo enorme e parado.

A soma da vida é nula.

Mas a vida tem tal poder: na escuridão absoluta, como líquido, circula.

Suicídio, riqueza, ciência... A alma severa se interroga. e logo se cala. E não sabe, se é noite, mar ou distância.

Triste farol da Ilha Rasa.

\section{Noturno alla finestra dell'appartamento}

Silenzioso cubo di tenebra: un salto, e sarebbe la morte. Ma è soltanto, sotto il vento, 1 'integrazione nella notte.

Nessun pensiero d'infanzia né nostalgia né vano proposito. Esclusivamente la contemplazione di un mondo enorme e immobile.

La somma della vita è nulla.

Ma la vita ha questo potere: nell'oscurità assoluta, come un liquido circola.

Suicidio, ricchezza, scienza...

L'anima severa si interroga E subito tace. E non sa, se è notte, mare o distanza.

Triste faro dell'Isola Rasa. 
A questão temática, como visto, sobrepõe-se à questão formal. Tabucchi apresenta ao leitor italiano uma versão da poesia de Drummond, que aparentemente se mostra de fácil tradução. Percebemos que a tradução serve, primeiro, como exercício, como leitura e reescrita de uma língua para outra, mas que, em um momento posterior, interessa ao tradutor-escritor reinventar o poema em outro gênero textual: a prosa. Assim, a tradução não se esgota em si, não podendo ser pensada como um "produto final", mas como um processo, uma transferência entre sistemas literários de sentidos, de uma concepção de mundo, além de uma reinvenção, neste caso, textual. Não é, portanto, só um fenômeno linguístico e/ou cultural pois, como vimos, Tabucchi não só traduz Drummond como "reescreve" Drummond em outro gênero, reinterpretando-o e inserindo-o no campo literário italiano por meio da sua própria atividade de escrita.

O texto poético drummondiano é transposto para outro sistema, se consideramos, com Jakobson, que a tradução implica "duas mensagens equivalentes, em dois códigos diferentes" e que na operação da tradução, "o que se traduz é um processo de construção de sentido e não as mensagens e suas denotações" (FALEIROS, 2012, p. 18). Assim, a tradução da poesia de Drummond feita pelo escritor italiano passa a ser vista também como "leitura, releitura e ressignificação", pois como notam Peterle, Santurbano e Wataghin:

traduzir, de fato, uma obra significa lidar também com duas tradições literárias (a de partida e a de chegada). Esta ação, a de traduzir, faz circular um texto fora da sua tradição e a consequência é uma (ou mais) releitura(s) e a disseminação do texto e dos hábitos e princípios que estão ali, muitas vezes, ocultos (PETERLE, SANTURBANO, WATAGHIN, 2011, p. 102-3).

Para além disso, Tabucchi empreende um processo mais amplo, de inserção da poesia drummondiana no contexto da narrativa italiana, assim como faz, em maior medida com a poesia de Pessoa, possibilitando um diálogo fecundo e produtivo entre a poesia e a prosa, entre a literatura brasileira e a italiana.

\section{Referências}

BASSNETT, S. Estudos de Tradução. Tradução de Vivina de Campos Figueiredo. Lisboa: Gulbenkian, 2003.

DRUMMOND DE ANDRADE, C. Sentimento del mondo.Trad. Antonio Tabucchi. Torino: Einaudi, 1987. 
FALEIROS, A. Traduzir o poema. São Paulo: Ateliê Editorial, 2012.

GLEDSON, J. “Drummond em inglês". In: Influências e impasses. Drummond e alguns contemporâneos. Trad. Frederico Dentello. São Paulo: Companhia das Letras, 2003.

MOURA, M. M. Posfácio a Sentimento do mundo. São Paulo: Companhia das Letras, 2012.

PETERLE, P., SANTURBANO, A., WATAGHIN, L. “A literatura italiana traduzida no sistema literário nacional: um percurso entre 1900 e 1950". In: A literatura italiana no Brasil e a literatura brasileira na Itália: sob o olhar da tradução. (Org.) Patricia Peterle. Tubarão: Copiart, 2011.

TABUCCHI, A. Introduzione a Sentimento del mondo. In: DRUMMOND DE ANDRADE, C. Sentimento del mondo.Trad. Antonio Tabucchi. Torino: Einaudi, 1987.

Recebido em 06/04/2017

Aprovado em 09/07/2017 